\title{
Short Photoperiods Impair Spatial Learning and Alter Hippocampal Dendritic Morphology in Adult Male White-Footed Mice (Peromyscus leucopus)
}

\author{
Leah M. Pyter, Brenda F. Reader, and Randy J. Nelson \\ Departments of Neuroscience and Psychology and Institute of Behavioral Medicine Research, Ohio State University, Columbus, Ohio 43210
}

\begin{abstract}
Although seasonal changes in brain morphology and function are well established in songbirds, seasonal plasticity of brain structure and function remain less well documented in mammals. Nontropical animals display many adaptations to reduce energy use to survive winter, including cessation of reproductive activities. Because of the high energetic costs of brain tissue, we hypothesized that male white-footed mice (Peromyscus leucopus) would reduce brain size in response to short days as well as regress their reproductive systems. Because short days may decrease hippocampal volume and impair spatial learning and memory in rodents and because of the potential for seasonal plasticity in the hippocampus, we hypothesized that photoperiod alters hippocampal morphology to affect spatial learning and memory. Mice housed in either long or short days for 10 weeks were examined for performance in a water maze; brains were then removed and weighed, and hippocampal volumes were determined. We also measured dendritic morphology and spine density in the CA1, CA3, and dentate gyrus. Short days decreased brain mass and hippocampal volume compared with long days. Short days also impaired long-term spatial learning and memory relative to long days but did not affect sensory discrimination or other types of memory. Short days decreased apical (stratum lacunosum-moleculare) CA1 spine density, as well as increased basilar (stratum oriens) CA3 spine density. Results from this study suggest that photoperiod alters brain size and morphology, as well as cognitive function. Understanding the mechanisms mediating these photoperiod-induced alterations may provide insight for treatment of seasonal cognitive and affective disorders.
\end{abstract}

Key words: seasonality; photoperiod; spatial learning and memory; hippocampus; spine density; dendritic complexity

\section{Introduction}

Photoperiod (day length) is a reliable cue by which organisms determine the time of year and coordinate adaptations to seasonal changes in their environment (Goldman, 2001). In nontropical environments, energy-conserving, adaptive adjustments occur among individuals in response to decreasing day lengths that are believed to promote survival during the harsh conditions of winter (Bronson, 1985). For example, short days decrease reproductive system size and function in white-footed mice (Peromyscus leucopus) (Whitaker, 1940; Ruf et al., 1997).

In addition to reproductive involution, individuals of several species also decrease brain mass or specific brain region volume in winter (nonbreeding season) compared with summer (breeding season) (Yaskin, 1984; Smith et al., 1997; Tramontin et al., 1998; Tramontin and Brenowitz, 2000). The brain uses far more energy per mass than other tissues, and any reduction would have significant energetic savings, especially during the winter (Jacobs,

Received Feb. 28, 2005; revised March 22, 2005; accepted March 29, 2005.

This work was supported by National Institutes of Health (NIH) Grants MH 57535 and MH 66144 and by National Science Foundation Grant IBN 04-16897. Additional support was received from NIH Grant P30NS045758. We thank Jaimie Adelson, Jessica Trent, Sandra Pieke-Dahl, Erica Glasper, Tara Craft, Georgia Bishop, Gretchen Neigh, Lynn Martin, and Brian Trainor for technical advice, manuscript advice, and assistance.

Correspondence should be addressed to Leah M. Pyter, Ohio State University, 48A Townshend Hall, Columbus, $\mathrm{OH}$ 43210. E-mail: pyter.1@osu.edu.

DOI:10.1523/JNEUROSCI.0795-05.2005

Copyright $\odot 2005$ Society for Neuroscience $\quad$ 0270-6474/05/254521-06\$15.00/0 1996b). In songbirds, seasonal changes in size and morphology of the brain circuitry mediating song is well established (Brenowitz et al., 1997; Smith et al., 1997; Tramontin et al., 2001). However, studies of seasonal plasticity of mammalian brain structure and function are sparse (for review, see Hofman and Swaab, 2002). Much of the work in rodents has focused on sexual dimorphisms of specific brain regions (Gaulin and FitzGerald, 1989; Jacobs, 1996a). Reduced hippocampal mass and volume have been reported in a few rodent species trapped during the winter or exposed to short day lengths (Yaskin, 1984; Perrot-Sinal et al., 1998; Galea and McEwen, 1999). Furthermore, deficits in spatial learning and memory (behaviors that require an intact hippocampus) (Morris et al., 1982) have been reported in short-day relative to long-day rodents (Perrot-Sinal et al., 1998). Spatial memory performance may be decreased during the nonbreeding season when home range size is smaller and roaming to find mates is decreased compared with during the breeding season (Stickel, 1968).

We hypothesized that photoperiod triggers morphological changes in the brain that underlie seasonal adjustments in behavior to promote energetic savings. This hypothesis is supported by spatial learning and memory research in food-storing and broodparasitic birds and other species (Sherry et al., 1992; Healy et al., 2005).

The hippocampus is among the most plastic sites in adult mammalian brains (McEwen, 1999; Breedlove and Jordan, 
2001). Changes within the hippocampus include fluctuations in dendritic complexity, spine density, soma size, neurogenesis, and apoptosis and may be associated with altered learning and memory performance (Moser et al., 1994; Woolley, 1998; O'Malley et al., 2000). The goal of this study was to test the hypothesis that short days would decrease hippocampal dendritic complexity and spine density in addition to specifically impairing spatial learning and memory.

We established that short days reduced brain size and hippocampal volume and confirmed previously reported short-day deficits in spatial learning and memory. Additionally, we discovered that photoperiod treatment affected neuronal spine density in the hippocampus. Overall, these data suggest that the functional learning and memory deficits exhibited by short-day mice are associated with structural changes in the hippocampus and reveal that adult mammalian brains display seasonal plasticity.

\section{Materials and Methods Experiment 1}

Animals

Twenty adult male ( $>55 \mathrm{~d}$ of age) white-footed mice (P. leucopus) from a breeding colony maintained at Ohio State University were used in this study. Breeder mice were originally obtained from the Peromyscus Genetic Stock Center at the University of South Carolina (Columbia, SC). All mice were housed in polypropylene cages $(27.8 \times 7.5 \times 13 \mathrm{~cm})$ with a constant temperature and humidity of $21 \pm 5^{\circ} \mathrm{C}$ and $50 \pm 10 \%$, respectively, and ad libitum access to food (8640 rodent diet; Harlan Teklad, Indianapolis, IN) and filtered tap water. Mice were housed either in long photoperiods (long-day; $n=7$ ) with a reversed 16/8 h light/dark cycle [lights on at 11:00 P.M. Eastern Standard Time (EST)] or in short pho-

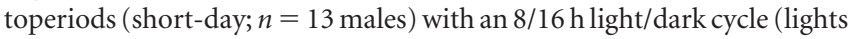
on at 7:00 A.M. EST) for 13 weeks. Mice were undisturbed except for routine cage changes and biweekly body mass measurements until week 10 , when behavioral testing commenced. Mice that failed to regress their gonads in response to short days were dropped from the study $(n=4)$. All studies were conducted with approval of the Ohio State Institutional Animal Care and Use Committee approval and in compliance with all United States federal animal welfare requirements.

\section{Sensory tests}

Mice were examined for potential photoperiod-induced differences in sensory discrimination before water-maze training. Visual placing was assessed by suspending mice by their tail and noting the first observable extension of forearms when lowering mice onto a wire grid from a height of $30 \mathrm{~cm}$ (Hatcher et al., 2001). Mice were scored from 0 to 4 for forearm extension ( 0 , none; 1 , on nose contact; 2 , on vibrissa contact; 3 , before vibrissa contact; and 4 , early vigorous extension). Tactile discrimination was determined by the presence or absence (scored as 1 or 2 , respectively) of a directed head movement in response to brushing a cotton-tipped applicator on the underside of the whiskers. Olfactory and auditory discriminations were tested after the water-maze training at the beginning of the dark phase (3:00-6:00 P.M.). For the olfactory testing, a modified "find the cookie" paradigm was used. Individual mice were placed in a clean cage for $3 \mathrm{~min}$ while a $1 \mathrm{~cm}$ piece of fruit (orange) was buried in the corner of the home cage. Mice were then returned to their home cages, and latency to uncovering the fruit was recorded for up to 300 s. For auditory discrimination, acoustic startle was tested using a single ventilated startle chamber (SR-Lab; San Diego Instruments, San Diego, CA). Mice were placed inside a clear, nonrestrictive Plexiglas cylinder within the chamber that was hooked up to an electrostatic sensor that measured the amplitude (in millivolts) of displacement caused by the animal's movement. The mice were subjected to a series of acoustic startle trials (120 dB pulse for a duration of $40 \mathrm{~ms}$ ) with an average of $15 \mathrm{~s}$ between each trial. The average amplitude (in millivolts) transduced by the animal's movement was used to determine the acoustic startle response. Before onset of the testing session, mice were allowed to acclimatize to the apparatus for $10 \mathrm{~min}$.

\section{Learning and memory tests}

Morris water maze. The water maze was used to test long-term spatial learning and memory (Morris, 1984). Testing occurred during the light phase (between 7:00 and 11:00 A.M.). The maze consisted of a white tank ( $1.3 \mathrm{~m}$ diameter) filled with $27^{\circ} \mathrm{C}$ water to a depth of $47.5 \mathrm{~cm}$. The water was made opaque with white nontoxic tempera paint. The maze was divided into four equal quadrants, and release points were designated at each quadrant as north, east, south, and west. Fixed extramaze cues in the form of large black geometric shapes surrounded the tank. A tracking video camera was suspended from the ceiling above the pool, and 2020 PLUS tracking software (HVS Image, Buckingham, UK) was used. Mice were handled using a small fishing net to avoid the stress of direct handling. On day 1, mice were allowed to swim freely for $60 \mathrm{~s}$ without a platform to acclimate to the pool. On days $2-9$, a platform $(9 \mathrm{~cm}$ diameter) was hidden $0.5 \mathrm{~cm}$ below the water surface in one quadrant. Mice were given $60 \mathrm{~s}$ to locate the hidden platform from random release points around the pool to "escape" from the water three times per day. On reaching the platform or after $60 \mathrm{~s}$, mice were placed on the platform for $10 \mathrm{~s}$ and then returned to the home cage. The intertrial intervals were $15 \mathrm{~s}$ during which the pool was skimmed of debris. Latency to reach the platform, the distance of the mouse's path, and swim speed were recorded by the system for each trial to assess acquisition of the spatial task. After the third trial of the day, each mouse received a piece of tissue paper in their cage to expedite drying. On day 10, the platform was removed, and a $60 \mathrm{~s}$ probe trial was run to examine retention of spatial memory. The percentage of time spent in each quadrant (including the quadrant in which the platform had been) was recorded. To evaluate reversal learning, the platform was repositioned in a different quadrant, and retraining to the new location on days 11-15 was completed as described previously. A second probe trial followed reversal training on day 16 . On day 17 , a single $60 \mathrm{~s}$ visible-platform trial was run to determine general visual acuity of the mice in this paradigm. The visual platform $(9 \mathrm{~cm}$ diameter $)$ was raised $0.5 \mathrm{~cm}$ above water level and encircled with a black rim. Latency to reach the platform was recorded.

Spontaneous alternation in a $Y$ maze. On completion of the water-maze task, spontaneous alternation behavior was recorded to assess working memory performance with a spatial component during the dark phase (Crawley, 2000). The maze was made of black Plexiglas and covered with clear Plexiglas to prevent escape during testing. Each arm was $35 \mathrm{~cm}$ and converged at an equal angle. Mice were placed in one arm and allowed to move freely through the maze during a 3 min session. The series of arm entries was recorded. An alternation was defined as entries into all three arms on consecutive occasions. The percentage of alternation was calculated using the following formula: (actual alternations/maximum possible alternations) $\times 100$. The maximum possible number of alternations was calculated as the total number of arm entries -2 .

Passive avoidance. Twenty-four hours after spontaneous alternation testing, mice were tested for cued and contextual conditioning memory (nonspatial) using passive avoidance during the dark phase. On day 1 of testing, mice were placed in one chamber of a dark two-chambered box separated by a door (San Diego Instruments). After 30 s of acclimation, a house light in the chamber in which the mouse resided was turned on, and the door was opened. To escape the light, mice entered the other chamber (which remained dark) where they received a $0.06 \mathrm{~mA}$ electrical shock ( $1 \mathrm{~s}$ duration) from the grid floor. Mice were then returned to their home cage. On day 2 , the same procedure was followed, except the shock was removed. In general, mice that learn to avoid the location of the aversive shock are slow to enter the dark chamber. Latency to enter the dark chamber was recorded to a maximum of $300 \mathrm{~s}$.

\section{Tissue collection and histology}

Twenty-four hours after the completion of all behavioral testing, mice were rapidly decapitated. Paired testes were removed and weighed to determine reproductive responsiveness to photoperiod treatment. The average testes mass for long-day mice was determined, and short-day males with a testes mass 2 SD below this mean were considered reproductively responsive to short days and excluded from the study $(n=4)$. Brains were removed and processed for Golgi staining according to the manufacturer's protocol (FD Rapid GolgiStain kit; FD Neurotechnolo- 
gies, Ellicott City, MD). Throughout the hippocampus, brains were cut coronally in $80 \mu \mathrm{m}$ sections on a cryostat and mounted on $3 \%$ gelatincoated slides before staining. Sections were also counterstained with cresyl violet. Granule cells in the dentate gyrus $(n=10$ per mouse) and pyramidal cells in the CA 1 and CA 3 regions ( $n=5-10$ per mouse) were traced using a camera lucida at $400 \times$ magnification (Neurolucida; MicroBrightField, Williston, VT). Neurons chosen for tracing met the following criteria: (1) they were completely impregnated with Golgi stain, (2) they were not obscured by other impregnated neurons or precipitant, and (3) all dendrites were visible within the plane of focus. The hemispheric location of the traced neurons was chosen randomly. Additionally, dendritic spines were traced on five $10 \mu \mathrm{m}$ distal dendritic segments of each neuron at $1000 \times$ magnification of randomly chosen granule cells (throughout the stratum moleculare) and pyramidal cells [throughout the stratum oriens (basilar) and the stratum lacunosum-moleculare (apical)] that had at least one branch point. Using the accompanying software (NeuroExplorer; MicroBrightField), dendritic complexity (via Sholl analysis), dendritic length, cell body area, and spine density were calculated. The Sholl analysis defines dendritic complexity by the number of dendritic branch points at fixed intervals from the cell bodies (Sholl, 1956). All samples were number-coded, and the experimenter was blind to the treatments.

\section{Experiment 2}

Sixteen adult male white-footed mice were housed in either long days $(n=8)$ or short days $(n=8)$ for 14 weeks. Mice were undisturbed except for routine cage changes and biweekly body mass measurement. At week 14 , mice were deeply anesthetized with sodium pentobarbital (Nembutal; Abbott Laboratories, North Chicago, IL) and transcardially perfused with $50 \mathrm{ml}$ of saline followed by $75 \mathrm{ml}$ of $10 \%$ phosphate-buffered formalin. Brains were removed and postfixed in formalin for at least $24 \mathrm{~h}$ at room temperature and then transferred to $15 \%$ sucrose in formalin at $4^{\circ} \mathrm{C}$ overnight. Finally, brains were transferred to $30 \%$ sucrose in $0.1 \mathrm{M}$ PBS at $4^{\circ} \mathrm{C}$ until permeated. Brains were frozen on dry ice and punctured with three stickpins on a rostrocaudal plane through the medial ventral area of the brain. These pinholes were used as reference points to orient the traced sections for volume reconstruction. Brains were then stored at $-70^{\circ} \mathrm{C}$ until being cut in $35 \mu \mathrm{m}$ sections on a cryostat at $-22^{\circ} \mathrm{C}$. Every sixth section throughout the hippocampus (from bregma -1.06 to -2.92) (Franklin and Paxinos, 1997) was dry-mounted on 3\% gelatincoated slides, dried overnight, and then stored at $-20^{\circ} \mathrm{C}$ until they were stained with $2.5 \%$ cresyl violet. The orientation and sequence of sections were kept consistent. Slides were then coverslipped with Permount (Fisher Scientific, St. Louis, MO). The hippocampus (dentate gyrus and Ammon's horn) and the outline of the surrounding telencephalon were traced at $40 \times$ using a camera lucida. Means \pm SEM of $15 \pm 1.07$ sections were traced per mouse. Using NeuroExplorer, three-dimensional representations of the hippocampus and the telencephalon were created by stacking the tracings in order. Volumes of these structures were calculated based on the Cavalieri method (Gundersen and Jensen, 1987). Relative hippocampal volumes were calculated by dividing the absolute hippocampal volume by the volume of the surrounding telencephalon. All samples were number-coded, and the experimenter was blind to the treatments.

\section{Statistical analyses}

Repeated-measures ANOVAs were used to compare water-maze performance over time. Within days, pair-wise comparisons were planned a priori in the analysis models and conducted using two-tailed Student's $t$ tests (Keppel, 1991). Student's $t$ tests were also used for other behavioral and physiological comparisons. Data with unequal variances were compared using nonparametric Mann-Whitney tests to compare photoperiod differences. One-tailed $t$ tests were used to compare hippocampal volume because of our a priori hypothesis. All comparisons were considered statistically significant when $p<0.05$. StatView version 5.0 .1 software was used for all analyses (SAS Institute, Cary, NC).

\section{Results}

\section{Short days decrease tissue masses}

Exposure to short days for 13 weeks decreased body mass (longday, $21.3 \pm 0.8 \mathrm{~g}$; short-day, $19.5 \pm 0.7 \mathrm{~g}$ ), testes mass (long-day, $203.5 \pm 11.0 \mathrm{mg}$; short-day, $74.1 \pm 9.0 \mathrm{mg}$ ), and brain mass (long-day, $539.8 \pm 6.5 \mathrm{mg}$; short-day, $509.6 \pm 16.0 \mathrm{mg})(p<$ 0.05 in all cases). Photoperiod treatment had no effect on visual, tactile, olfactory, or auditory discrimination (Table 1) $(p>0.05$ in all cases).

\section{Short days impair Morris water-maze performance}

Short days increased the latency to reach the hidden platform and the distance traveled to reach the hidden platform after seven and eight blocks of trials in the water-maze test (Fig. $1 A, B)(p<0.05$ in all cases). The overall effect of photoperiod on latency and path length taken to reach the hidden platform were statistically nonsignificant ( $p=0.08$ and 0.1 , respectively). However, all animals displayed some degree of learning because both the latency and distance to reach the platform decreased over time $(p<0.001$ in both cases). Swim speed, a possible indication of motivation, did not differ at any time point in the hidden-platform trials (data not shown). All mice spent more time in the quadrant in which the platform had been removed for the probe trial (data not shown) $(p<0.05)$; however, there were no differences between long-day- or short-day-treated mice $(p>0.05)$.

Similar to the initial hidden-platform trials, short days increased the latency to reach the hidden platform and the distance swam to reach the hidden platform on block 3 of the reversal learning training (Fig. $2 A, B)(p<0.05$ in both cases). All mice displayed reversal learning to some degree because latency and distance to reach the platform decreased over time $(p<0.05$ in both cases). Again, swim speed did not differ between photoperiod groups at any time point (data not shown) $(p>0.05)$. Short-day mice also displayed impaired reversal learning during the probe trial after reversal training. Short-day mice spent significantly more time than long-day mice in the quadrant of the pool in which the platform had been hidden during the original hidden-platform trials (Fig. $2 C)(p<0.05)$, whereas short-day mice spent less time than long-day mice in the quadrant of the pool in which the platform had been removed from the recent reversal train-

\section{Table 1. Mean \pm SEM behavioral scores after 10 weeks of long or short days}

\begin{tabular}{lcc}
\hline Sensory test & Long-day & Short-day \\
\hline Visual discrimination & $2.1 \pm 0.1$ & $2.4 \pm 0.1$ \\
Vibrissa discrimination & $1.5 \pm 0.2$ & $1.4 \pm 0.1$ \\
Olfactory latency (s) & $171.3 \pm 30.8$ & $172.6 \pm 36.4$ \\
Auditory discrimination (\% startle) & $45.1 \pm 7.6$ & $33.1 \pm 3.5$ \\
\hline
\end{tabular}

A)

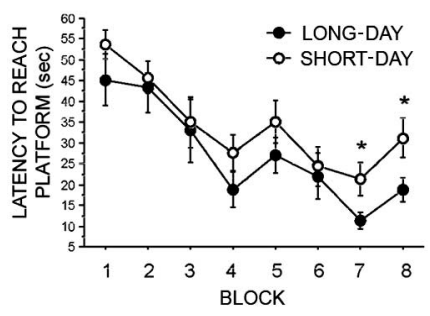

B)

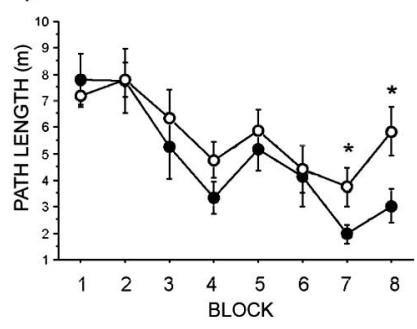

Figure 1. Photoperiod-induced differences in spatial learning (via water maze). $\boldsymbol{A}$, Latency to reach the hidden platform by block of training. $\boldsymbol{B}$, Path length to reach the hidden platform by block of training. Each block represents three trials. Long-day, $n=7$; short-day, $n=9 .{ }^{*} p<0.05$. 
ing, although this difference did not reach statistical significance $(p=0.1)$.

\section{Short days do not affect nonspatial learning and memory}

Photoperiod treatments did not affect the percentage of spontaneous alternation or the total number of possible alternations (a measure of locomotor activity) (data not shown) ( $p>0.05$ in both cases).

Both long-day and short-day mice hesitated before stepping through to the side of the chamber that previously shocked them in the passive avoidance test (day 1 : long-day, $12.3 \pm 4.1 \mathrm{~s}$; short-day, $6.3 \pm$ $0.9 \mathrm{~s}$; day 2: long-day, $43.6 \pm 29.2 \mathrm{~s}$; shortday, $24.3 \pm 9.9 \mathrm{~s})$. However, only the short-day mice hesitated to step over significantly longer on day $2(p<0.05)$.

\section{Short days affect spine density}

Photoperiod treatment did not affect dendritic complexity in the CA1, CA3, or dentate gyrus regions (Fig. $3 A-C)(p>0.05$ in all cases). Raw dendritic length also did not differ between photoperiod-treated groups in any of the hippocampal regions examined (data not shown) $(p>0.05$ in all cases). However, short days decreased spine density on the terminal tips (stratum lacunosummoleculare) of both CA1 $(p<0.05)$ and CA3 $(p=0.1)$ pyramidal cells compared with long days (Fig. $4 A, C$ ). On the other hand, short days increased spine density on basilar tips (stratum oriens) of CA3 dendrites (Fig. $4 B)(p<0.05)$ but had no effect on spine density in basilar dendritic tips (stratum oriens) of pyramidal cells in the CA1 or dendritic tips (stratum moleculare) in the dentate gyrus $(p>0.05)$. Cell body area did not differ between photoperiods in the CA1, CA3, or dentate gyrus regions (data not shown) $(p>0.05$ in all cases).

\section{Short days decrease hippocampal volume}

Short days decreased both absolute (long-day, $4.50^{-10} \pm 9.4^{-9}$ $\mu \mathrm{m}^{3}$; short-day, $2.86^{-10} \pm 3.3^{-9} \mu \mathrm{m}^{3}$ ) and relative (hippocampus volume/telencephalon volume; long-day, $1.07 \pm 0.7$; shortday, $0.22 \pm 0.1$ ) hippocampal volume compared with long days ( $p<0.05$ in both cases). There were no differences in the volume of the telencephalic region surrounding the hippocampus between the photoperiod-treated groups (long-day, $10.2^{-10} \pm$ $3.4^{-10} \mu \mathrm{m}^{3}$; short-day, $\left.14.1^{-10} \pm 1.9^{-10} \mu \mathrm{m}^{3}\right)(p>0.05)$.

\section{Discussion}

In this study, we observed that short days impaired both spatialspecific learning and memory relative to long days without affecting sensory abilities. Specifically, short-day mice required longer to find a hidden platform in the water maze and spent less time in the quadrant with the platform compared with long-day mice. Furthermore, photoperiod treatment induced changes in hippocampal morphology such that short days decreased apical spine density in the CA1 region of the hippocampus and hippocampal volume and increased basilar spine density in the CA3 region compared with long days.

We hypothesized that, in addition to inhibiting the reproductive system, short days would trigger morphological changes in
B)

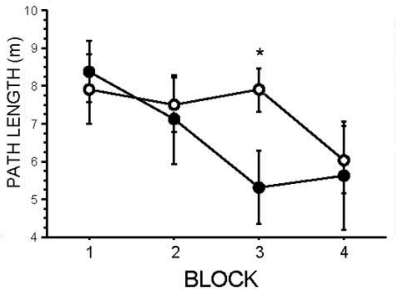

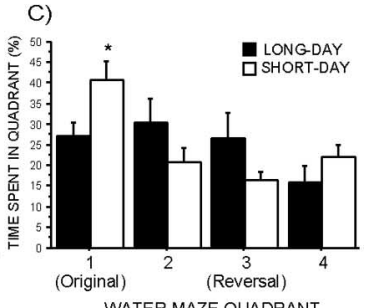

WATER MAZE QUADRANT

Figure 2. Photoperiod-induced differences in water-maze reversal learning and memory after relocation to the hidden plat, Latency to reach the relocated hidden platform by block of training. $\boldsymbol{B}$. Path length to reach the hidden platform by block

Figure 3. Effects of photoperiod on dendritic complexity (via Sholl analysis) of hippocampal neurons. $A$, Pyramidal neuron complexity in the CA1 region ( $n=5-10$ neurons per brain). $\boldsymbol{B}$, Pyramidal neuron complexity in the CA3 region $(n=5-10$ neurons per brain). $C$, Granule neuron complexity in the dentate gyrus ( $n=10$ neurons per brain).
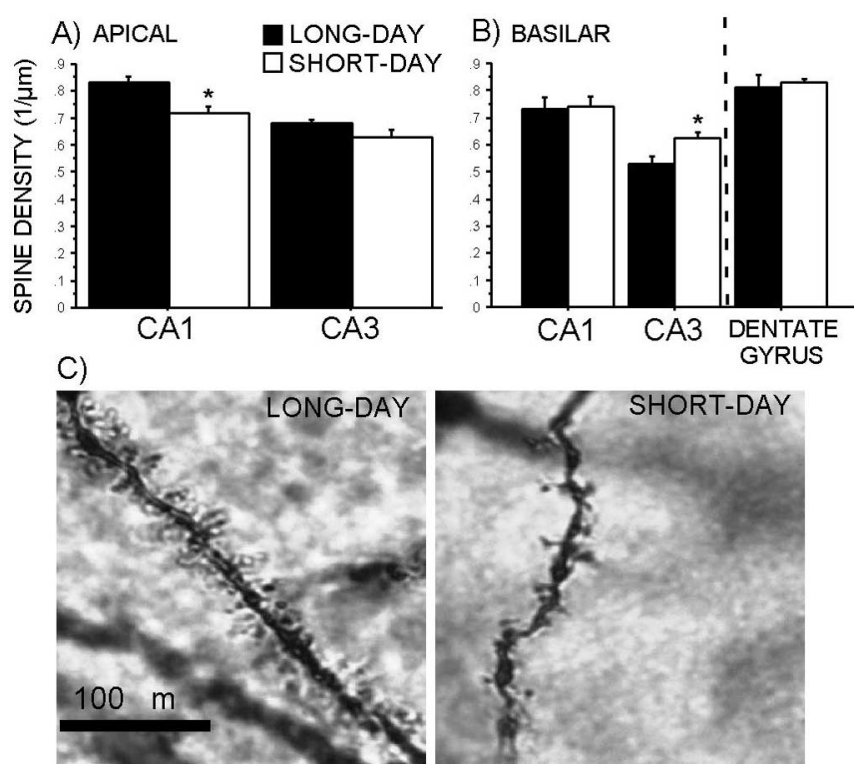

Figure 4. Effects of photoperiod on spine density on terminal tips of hippocampal dendrites. $\boldsymbol{A}$, Spine density of apical tips of pyramidal dendrites in CA1 and CA3 regions. $\boldsymbol{B}$, Spine density of basilar tips of pyramidal dendrites in CA1 and CA3 regions and of granule cells in the dentate gyrus. C, Photomicrographs of apical spines in CA1 of long-day (left) and short-day (right) mice; magnification, $1000 \times$. The dotted line represents the unipolarity of granule cells in the dentate gyrus; $n=$ five $10 \mu \mathrm{m}$ dendritic segments of spines per neuron. ${ }^{*} p<0.05$.

the hippocampus that mediate seasonal deficits in learning and memory. The short-day impairment of spatial learning and memory in the water maze supported previous findings in nonbreeding deer mice (Peromyscus maniculatus) (Galea et al., 1994; Perrot-Sinal et al., 1998). We also showed that reversal learning and memory for the reversal platform location are compromised. 


\section{Selective impairment of spatial memory in short days}

We also tested whether spatial memory is specifically impaired compared with other types of memory based on the hypothesis that spatial memory deficits are derived from the shrinkage of the $P$. leucopus home range during the nonbreeding season (Stickel, 1968). The selective impairment of long-term spatial learning and memory is supported based on our results from the spontaneous alternation and passive avoidance tests. Additional tests of this hypothesis require experiments using multiple long-term spatial tasks (e.g., radial arm maze). However, controls for photoperiod-induced differences in motivation to eat and locomote are difficult to equalize in these tests that are dependent on food motivation.

\section{Photoperiodic differences in spine density}

In rats, spine density of the dentate gyrus and CA1 region of the hippocampus has been positively correlated with water-maze learning and memory performance (Moser et al., 1994; O’Malley et al., 2000). Spines increase the surface area of dendrites, which increase the excitatory synaptic density and number of connections between neurons (for review, see Sorra and Harris, 2000). Therefore, hippocampal spine density may be an indication of the efficiency of the synaptic network involved in spatial learning and memory. Similarly, our results indicate that apical spine density decreased in the CA1 pyramidal cells of short-day mice in conjunction with their impaired behavioral performance. In contrast to the impaired water-maze performance, however, basilar spine density increased in the CA3 region of short-day mice. The role of spine density among hippocampal regions and dendritic poles in learning and memory remains unspecified (Sorra and Harris, 2000). Photoperiod-induced changes in specific spine morphology remain to be characterized and may provide insight into the functional significance of the present alterations of spine density.

In addition to photoperiod, spine density in adult rodents is also affected by other environmental factors. For example, environmental enrichment (Diamond et al., 1976; Rampon et al., 2000) and awakening after hibernation (Popov et al., 1992) increase spine density in the hippocampus, whereas restraint stress decreases hippocampal spine density (Magarinos et al., 1999). These environment-induced changes in hippocampal spine density occur over varying amounts of time ( $2 \mathrm{~h}$ to $25 \mathrm{~d}$ ). The time course over which the present photoperiod-induced changes in spine density are established needs to be examined. Neurogenesis in the dentate gyrus, another example of adult hippocampal plasticity, may also be affected by photoperiod (Huang et al., 1998; Lavenex et al., 2000). Studies that test the hypothesis that differences in hippocampal neurogenesis between long-day and shortday mice modulate spatial learning and memory are under way in our laboratory.

\section{Photoperiodic differences in brain and hippocampal size}

Gross brain masses were low in voles and shrews trapped during the winter and in juvenile voles exposed to short days from birth (Yaskin, 1984; Dark et al., 1987). In the present study, short days decreased gross brain mass in adult male white-footed mice, both in absolute terms and after correcting for reduced body mass. Additionally, short-day mice had decreased hippocampal volumes, which is consistent with the hypothesis that polygynous (having multiple female mates) rodents increase spatial memory during the breeding season to acquire multiple mates, as well as the hypothesis that hippocampal volume is positively correlated with hippocampal function (i.e., spatial learning and memory)
(Gaulin and FitzGerald, 1986; Jacobs et al., 1990; Perrot-Sinal et al., 1998). Similarly, large seasonal variations in home range size have been described in field studies on Peromyscus such that home range sizes are dramatically smaller in the winter (nonbreeding season) relative to the summer (Metzgar, 1978). It is important to note that all previously published estimations of hippocampal volume were based on a formula designed to calculate the volume of a truncated cone as opposed to the more sensitive method of volume estimation used in this study (i.e., Cavalieri's method). In summary, we have linked short day-induced deficits in spatial learning and memory with whole brain and hippocampal involution. These data support the concept that the relative size of a brain region represents its functionality and is capable of displaying adaptive plasticity among seasons in adults (Tramontin and Brenowitz, 2000).

\section{Potential role of hormones on photoperiodic brain changes}

Because the duration of melatonin secretion is directly modulated by photoperiod and mediates many photoperiod-induced adaptations, melatonin is a likely hormonal candidate for a mechanism mediating the photoperiod-induced hippocampal modifications described in this report. Melatonin receptors are present in the hippocampal area (entorhinal cortex) of whitefooted mice (Weaver et al., 1990; Musshoff et al., 2002). The only model of seasonal plasticity in which the role of melatonin has been examined is in the neural song circuitry of songbirds (Bentley et al., 1999). However, melatonin also affects long-term potentiation in hippocampal slices of photoperiod nonresponsive animals (El-Sherif et al., 2003). Future study of the role of melatonin in seasonal hippocampal plasticity is warranted.

Decreased circulating testosterone and corticosterone concentrations in short-day white-footed mice (Feist et al., 1988) may also modulate morphological hippocampal alterations and result in the learning and memory behavior differences observed in this study. Although breeding condition has been associated with spatial learning and memory performance, the relationship between adult testosterone concentrations and spatial performance is not clear (Galea et al., 1995; Perrot-Sinal et al., 1998), although there appears to be a positive correlation between testosterone concentration and hippocampal volume (Perrot-Sinal et al., 1998; Galea et al., 1999). Additionally, sustained (i.e., chronic) corticosterone treatment or stress-induced increases in corticosterone inhibit learning and memory (for review, see Roozendaal, 2000) as well as decrease hippocampal dendritic complexity (for review, see McEwen and Magarinos, 1997) in various species. We are currently testing the possibilities that photoperiodic alteration of testosterone or corticosterone (basal or stress-induced via the water maze) concentrations mediate the changes described in the present study.

Taken together, the influence of the photoperiod on brain and behavioral plasticity in adults is likely profound in animals that reside in environments with dramatic seasonal changes. Before this study, the link between seasonal effects on brain structure and related function was primarily confined to the neural song circuitry in birds. We suggest that a parallel mammalian model of adult brain plasticity exists in the hippocampus and affects spatial learning and memory. Specifically, morphological changes in the hippocampus appear to underlie seasonal alterations in learning and memory performance. Future research investigating the mechanisms underlying this seasonal plasticity may be applicable to treatment of seasonal cognitive and affective disorders. 


\section{References}

Bentley GE, Van't Hof TJ, Ball GF (1999) Seasonal neuroplasticity in the songbird telencephalon: a role for melatonin. Proc Natl Acad Sci USA 96:4674-4679.

Breedlove SM, Jordan CL (2001) The increasingly plastic, hormoneresponsive adult brain. Proc Natl Acad Sci USA 98:2956-2957.

Brenowitz EA, Margoliash D, Nordeen KW (1997) An introduction to birdsong and the avian song system. J Neurobiol 33:495-500.

Bronson FH (1985) Mammalian reproduction: an ecological perspective. Biol Reprod 32:1-26.

Crawley JN (2000) What's wrong with my mouse? Behavioral phenotyping of transgenic and knockout mice. New York: Wiley.

Dark J, Dark KA, Zucker I (1987) Long day lengths increase brain weight and DNA content in the meadow vole, Microtus pennsylvanicus. Brain Res 409:302-307.

Diamond MC, Ingham CA, Johnson RE, Bennett EL, Rosenzweig MR (1976) Effects of environment on morphology of rat cerebral cortex and hippocampus. J Neurobiol 7:75-85.

El-Sherif Y, Tesoriero J, Hogan MV, Wieraszko A (2003) Melatonin regulates neuronal plasticity in the hippocampus. J Neurosci Res 72:454-460.

Feist CF, Feist DD, Lynch DR (1988) The effects of castration and testosterone on thermogenesis and pelage condition in white-footed mice (Peromyscus leucopus) at different photoperiods and temperatures. Physiol Zool 61:26-33

Franklin KBJ, Paxinos G (1997) The mouse brain in stereotaxic coordinates. San Diego: Academic.

Galea LA, McEwen BS (1999) Sex and seasonal differences in the rate of cell proliferation in the dentate gyrus of adult wild meadow voles. Neuroscience 89:955-964.

Galea LA, Kavaliers M, Ossenkopp KP, Innes D, Hargreaves EL (1994) Sexually dimorphic spatial learning varies seasonally in two populations of deer mice. Brain Res 635:18-26.

Galea LA, Kavaliers M, Ossenkopp KP, Hampson E (1995) Gonadal hormone levels and spatial learning performance in the Morris water maze in male and female meadow voles, Microtus pennsylvanicus. Horm Behav 29:106-125.

Galea LA, Perrot-Sinal TS, Kavaliers M, Ossenkopp KP (1999) Relations of hippocampal volume and dentate gyrus width to gonadal hormone levels in male and female meadow voles. Brain Res 821:383-391.

Gaulin SJ, FitzGerald RW (1986) Sex differences in spatial ability: an evolutionary hypothesis and test. Am Nat 127:74-87.

Gaulin SJ, FitzGerald RW (1989) Sexual selection for spatial-learning ability. Anim Behav 37:322-331.

Goldman BD (2001) Mammalian photoperiodic system: formal properties and neuroendocrine mechanisms of photoperiodic time measurement. J Biol Rhythms 16:283-301.

Gundersen HJ, Jensen EB (1987) The efficiency of systematic sampling in stereology and its prediction. J Microsc 147:229-263.

Hatcher JP, Jones DN, Rogers DC, Hatcher PD, Reavill C, Hagan JJ, Hunter AJ (2001) Development of SHIRPA to characterise the phenotype of gene-targeted mice. Behav Brain Res 125:43-47.

Healy SD, de Kort SR, Clayton NS (2005) The hippocampus, spatial memory and food hoarding: a puzzle revisited. Trends Ecol Evol 20:17-22.

Hofman MA, Swaab DF (2002) A brain for all seasons: cellular and molecular mechanisms of photoperiodic plasticity. Prog Brain Res 138:255-280

Huang L, DeVries GJ, Bittman EL (1998) Photoperiod regulates neuronal bromodeoxyuridine labeling in the brain of a seasonally breeding mammal. J Neurobiol 36:410-420.

Jacobs LF (1996a) Sexual selection and the brain. Trends Ecol Evol 11:82-86.

Jacobs LF (1996b) The economy of winter: phenotypic plasticity in behavior and brain structure. Biol Bull 191:92-100.

Jacobs LF, Gaulin SJ, Sherry DF, Hoffman GE (1990) Evolution of spatial cognition: sex-specific patterns of spatial behavior predict hippocampal size. Proc Natl Acad Sci USA 87:6349-6352.

Keppel G (1991) Design and analysis: a researcher's handbook, Ed 3. Englewood Cliffs, NJ: Prentice-Hall.

Lavenex P, Steele MA, Jacobs LF (2000) The seasonal pattern of cell proliferation and neuron number in the dentate gyrus of wild adult eastern grey squirrels. Eur J Neurosci 12:643-648.

Magarinos AM, Deslandes A, McEwen BS (1999) Effects of antidepressants and benzodiazepine treatments on the dendritic structure of CA3 pyramidal neurons after chronic stress. Eur J Pharmacol 371:113-122.

McEwen BS (1999) Stress and hippocampal plasticity. Annu Rev Neurosci 22:105-122.

McEwen BS, Magarinos AM (1997) Stress effects on morphology and function of the hippocampus. Ann NY Acad Sci 821:271-284.

Metzgar LH (1978) Dispersion patterns in a Peromyscus population. J Mammal 60:29-45.

Morris R (1984) Developments of a water-maze procedure for studying spatial learning in the rat. J Neurosci Methods 11:47-60.

Morris RG, Garrud P, Rawlins JN, O’Keefe J (1982) Place navigation impaired in rats with hippocampal lesions. Nature 297:681-683.

Moser MB, Trommald M, Andersen P (1994) An increase in dendritic spine density on hippocampal CA1 pyramidal cells following spatial learning in adult rats suggests the formation of new synapses. Proc Natl Acad Sci USA 91:12673-12675.

Musshoff U, Riewenherm D, Berger E, Fauteck JD, Speckmann EJ (2002) Melatonin receptors in rat hippocampus: molecular and functional investigations. Hippocampus 12:165-173.

O'Malley A, O'Connell C, Murphy KJ, Regan CM (2000) Transient spine density increases in the mid-molecular layer of hippocampal dentate gyrus accompany consolidation of a spatial learning task in the rodent. Neuroscience 99:229-232.

Perrot-Sinal TS, Kavaliers M, Ossenkopp KP (1998) Spatial learning and hippocampal volume in male deer mice: relations to age, testosterone and adrenal gland weight. Neuroscience 86:1089-1099.

Popov VI, Bocharova LS, Bragin AG (1992) Repeated changes of dendritic morphology in the hippocampus of ground squirrels in the course of hibernation. Neuroscience 48:45-51.

Rampon C, Tang YP, Goodhouse J, Shimizu E, Kyin M, Tsien JZ (2000) Enrichment induces structural changes and recovery from nonspatial memory deficits in CA1 NMDAR1-knockout mice. Nat Neurosci 3:238-244.

Roozendaal B (2000) 1999 Curt P. Richter award. Glucocorticoids and the regulation of memory consolidation. Psychoneuroendocrinology 25:213-238.

Ruf T, Korytko AI, Stieglitz A, Lavenburg KR, Blank JL (1997) Phenotypic variation in seasonal adjustments of testis size, body weight, and food intake in deer mice: role of pineal function and ambient temperature. J Comp Physiol [B] 167:185-192.

Sherry DF, Jacobs LF, Gaulin SJ (1992) Spatial memory and adaptive specialization of the hippocampus. Trends Neurosci 15:298-303.

Sholl DA (1956) The organization of the cerebral cortex. London: Wiley.

Smith GT, Brenowitz EA, Wingfield JC (1997) Seasonal changes in the size of the avian song control nucleus HVC defined by multiple histological markers. J Comp Neurol 381:253-261.

Sorra KE, Harris KM (2000) Overview on the structure, composition, function, development, and plasticity of hippocampal dendritic spines. Hippocampus 10:501-511.

Stickel LF (1968) Biology of Peromyscus (Rodentia). In: Home range and travels (King JA, ed), pp 373-411. Stillwater, OK: American Society of Mammologists.

Tramontin AD, Brenowitz EA (2000) Seasonal plasticity in the adult brain. Trends Neurosci 23:251-258.

Tramontin AD, Smith GT, Breuner CW, Brenowitz EA (1998) Seasonal plasticity and sexual dimorphism in the avian song control system: stereological measurement of neuron density and number. J Comp Neurol 396:186-192.

Tramontin AD, Perfito N, Wingfield JC, Brenowitz EA (2001) Seasonal growth of song control nuclei precedes seasonal reproductive development in wild adult song sparrows. Gen Comp Endocrinol 122:1-9.

Weaver DR, Carlson LL, Reppert SM (1990) Melatonin receptors and signal transduction in melatonin-sensitive and melatonin-insensitive populations of white-footed mice (Peromyscus leucopus). Brain Res 506:353-357.

Whitaker W (1940) Some effects of artificial illumination on the reproduction in the white-footed mouse, P. leucopus noveboracensis. J Exp Zool 83:33-60.

Woolley CS (1998) Estrogen-mediated structural and functional synaptic plasticity in the female rat hippocampus. Horm Behav 34:140-148.

Yaskin V (1984) Seasonal changes in brain morphology in small mammals. Pittsburgh: Carnegie Museum of Natural History. 